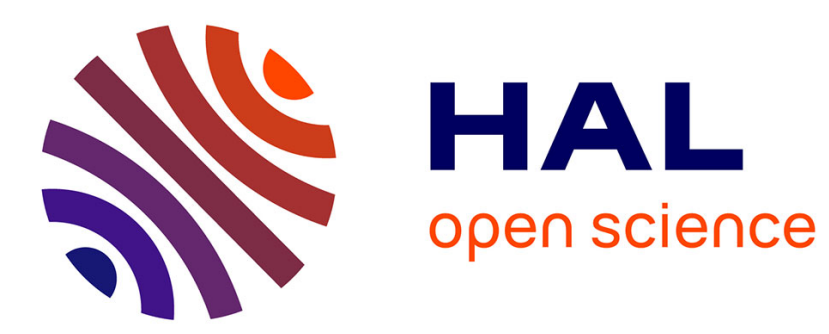

\title{
Synthesis of Macromolecules Containing Phenylalanine and Aliphatic Building Blocks
}

Delphine Chan-Seng, Jeroen Louwsma, Jean-François Lutz, Stéphane Joly

\section{To cite this version:}

Delphine Chan-Seng, Jeroen Louwsma, Jean-François Lutz, Stéphane Joly. Synthesis of Macromolecules Containing Phenylalanine and Aliphatic Building Blocks. Macromolecular Rapid Communications, 2018, 39 (8), pp.1700764. 10.1002/marc.201700764 . hal-02084939

\section{HAL Id: hal-02084939 \\ https://hal.science/hal-02084939}

Submitted on 29 Mar 2019

HAL is a multi-disciplinary open access archive for the deposit and dissemination of scientific research documents, whether they are published or not. The documents may come from teaching and research institutions in France or abroad, or from public or private research centers.
L'archive ouverte pluridisciplinaire HAL, est destinée au dépôt et à la diffusion de documents scientifiques de niveau recherche, publiés ou non, émanant des établissements d'enseignement et de recherche français ou étrangers, des laboratoires publics ou privés. 
This is the peer-reviewed version of the article Macromol. Rapid Commun. 2018, 39, 1700764 which has been published in final form at https://onlinelibrary.wiley.com/doi/abs/10.1002/marc.201700764

This article may be used for non-commercial purposes in accordance with Wiley policy

\title{
Synthesis of Macromolecules Containing Phenylalanine and Aliphatic Building Blocks
}

\author{
Delphine Chan-Seng, ${ }^{1, *}$ Jeroen Louwsma, ${ }^{2}$ Jean-François Lutz, ${ }^{1}$ Stéphane Joly ${ }^{2}$ \\ ${ }^{1}$ Université de Strasbourg, CNRS, Institut Charles Sadron, F-67000 Strasbourg, France \\ ${ }^{2}$ PSA Groupe, Site de Vélizy, Chemin de Gisy, 78943 Vélizy-Villacoublay, France \\ Corresponding author: Delphine Chan-Seng (delphine.chan-seng@ics-cnrs.unistra.fr)
}

\begin{abstract}
Aiming at developing efficient interfacial agents for fiber-reinforced composite materials, macromolecules were designed to have different components able to stick to the fiber and be compatible with the polymer matrix respectively. Herein, macromolecules were prepared by solid-phase synthesis considering phenylalanine residues to promote adsorption of the macromolecule on aramid fibers and aliphatic building blocks to interact with a hydrophobic polymer matrix. Using phenylalanine as building block for the preparation of macromolecules by iterative synthesis has been shown to be challenging. Thus, the screening of various parameters for the optimization of the synthesis of these macromolecules is discussed in this communication. A preliminary thermal study by thermal gravimetric analysis was conducted to evaluate their thermal stability.
\end{abstract}




\section{Introduction}

Developments in polymer chemistry permit the preparation of advanced polymers by controlling their topology, functionality and microstructure providing access to more elaborated architectures such as star, comb and hyperbranched polymers that could be bearing a variety of functional groups at well-defined sites on the polymer chain. The control of the microstructure of polymers has been mostly focused until now on the control of the tacticity, which offers the access to ordered structures such as helices and $\beta$-sheets, but also can influence the properties of the polymer. ${ }^{[1]}$ More recently, an increasing attention has been focused on the precise control of the sequence of polymers. The preparation of sequence-controlled polymers has been approached through various approaches based on kinetic considerations, catalysis, template chemistry, multicomponent reaction, (macro)molecular design, and iterative synthesis. ${ }^{[2-5]}$ While the control of the microstructure of polymers still remains a challenge for polymer chemists, the ability to tune the sequence of polymers would be an asset for applications in materials sciences. For example, van Zoelen et al. reported the preparation of sequence-specific polypeptoids based on hydrophobic and hydrophilic units used as coating on a surface. ${ }^{[6]}$ The authors demonstrated that the sequence had an effect on the antifouling or fouling release properties of this coating. Furthermore, the groups of Hutchison and Meyer have investigated the influence of monomer sequence on the optical and electronic properties of conjugated oligomers based for example on either unsubstituted and dialkoxy-substituted p-phenylenevinylene ${ }^{[7]}$ or benzothiadiazole and phenylenevinylene ${ }^{[8]}$ buildings blocks, systems for which the performance and properties were observed to be dependent of the sequence. From a theoretical approach, the group of Simmons recently investigated by molecular dynamics simulation the influence of the comonomer sequence on the interfacial energy when considering the design of copolymers as interfacial compatibilizers for polymer blends. ${ }^{[9]}$ Their results indicated that copolymers with specific sequences could potentially be more efficient to reduce the interfacial energy as compared to block and random copolymers. Furthermore, initial work on the use of sequence-defined macromolecules as interfacial agents for composite materials have been reported, e.g. peptide-polymer conjugates for composite materials based on $\mathrm{MgF}_{2}$ nanoparticles and poly(ethylene oxide). ${ }^{[10,11]}$

Herein a synthetic strategy is proposed to design interfacial agents in the attempt to promote an enhanced dispersion of aramid fibers in a polymer matrix through the synthesis of macromolecules possessing some building blocks able to adsorb onto the chosen fiber and others compatible with the polymer matrix. The synthetic route used is based on the solidsupported iterative approach following a protocol previously established to obtain sequence- 
defined macromolecules based on amino acid residues and aliphatic building blocks. ${ }^{[12]}$ The synthesis of macromolecules was prepared using L-phenylalanine, amino acid chosen to contribute to the adsorption onto aramid fibers, and synthetic building blocks such as 6-azidohexanoic acid as elements compatible with the polymer matrix (e.g. polypropylene). While the previously established protocol has been reported for some amino acids, its use with phenylalanine has been more problematic. This work focuses on gaining an understanding on the difficulties associated with the use of phenylalanine, but also providing some possible alternatives to overcome the difficulties encountered. Their thermal stability was investigated by thermogravimetry analysis (TGA) measurement to appraise the viability of these molecules considering the thermal processes used to prepare composite materials.

\section{Results and Discussion}

Macromolecules were synthesized by solid-phase synthesis from a conventional peptide resin by iterative addition of three types of building blocks per repetition cycles: i) L-phenylalanine (F, step a), ii) 6-azidohexanoic acid (h, step c) as spacing building block and iii) propargylamine as linker $(\bullet$, step d) as depicted on Figure 1. To prepare the macromolecule Fh $\bullet F h \bullet F h \bullet F h$, the first attempts used the reaction conditions reported previously ${ }^{[12]}$ using a 2-chlorotrityl chloride resin that was functionalized with Fmoc-Phe-OH (loading targeted $0.5 \mathrm{mmol}$ per gram of resin). Fmoc-Phe-OH and 6-azidohexanoic acid were attached to the free extremity of the macromolecule growing on the resin using 2-(1H-benzotriazol-1-yl)-1,1,3,3tetramethyluronium hexafluorophosphate (HBTU) as coupling agent in the presence of 1-hydroxybenzotriazole (HOBt) and $N, N$-diisopropylethylamine (DIPEA) in anhydrous $N, N$ dimethylformamide, while the addition of propargylamine was conducted by copper-assisted alkyne-azide cycloaddition reaction in the presence of copper(I) bromide and $N, N, N$, $N$ ', $N$ '’pentamethyldiethylenetriamine (PMDETA) in anhydrous dichloromethane (Table 1, entry 1). Each step was monitored using the Kaiser test to validate the absence (steps a and c) or presence (steps $\mathbf{b}$ and $\mathbf{d}$ ) of primary amines. The addition of Fmoc-Phe-OH was frequently observed to be incomplete, which is not something unusual as previously reported in the literature, ${ }^{[13]}$ and was thus performed twice systematically, i.e. a negative Kaiser test was observed after the repetition of step a. Additionally, measurements by infrared spectroscopy were performed for steps $\mathbf{c}$ and $\mathbf{d}$ to verify especially the complete addition of propargylamine (i.e. complete disappearance of the characteristic absorbance band of azide groups at $2100 \mathrm{~cm}^{-1}$ after conducting step d). Four repetition cycles were performed to prepare these macromolecules while the fourth cycle consisted solely in the addition of Fmoc-Phe-OH and 6-azidohexanoic acid as building blocks. After cleavage from the resin using a solution of trifluoroethanol in 
dichloromethane, the macromolecules were isolated by precipitation in diethyl ether and their structural integrity was examined by NMR spectroscopy and mass spectrometry. The ${ }^{1} \mathrm{H}$ NMR spectrum pemitted the identification of each building blocks: (i) phenylalanine (F) residues at 7.0-7.3 ppm (aromatic protons) and 2.7-3.0 ppm (methylene of $\mathbf{F}$ ), (ii) spacers (h) at $4.2 \mathrm{ppm}$ (methylene next to the triazole ring) and $2.0 \mathrm{ppm}$ (methylene next to the amide linkage) for example, and (iii) linker $(\bullet)$ at $7.7 \mathrm{ppm}$ (protons of triazole). Furthermore, the mass spectrometry after electrospray ionisation (ESI-MS) spectrum revealed the presence of the targeted macromolecule $\left([\mathrm{M}+\mathrm{Na}]^{+} 1350.70\right.$ as expected by calculation from $\left.\mathrm{C}_{69} \mathrm{H}_{89} \mathrm{~N}_{19} \mathrm{O}{ }_{9} \mathrm{Na}\right)$ along with peaks corresponding to molecules having missing building blocks due to their incomplete addition during the iterative synthesis (e.g. $[(\mathrm{M}-\mathrm{F})+\mathrm{Na}]^{+}$at 1203.63$)$, but also some undefined impurities (Figure 2a).
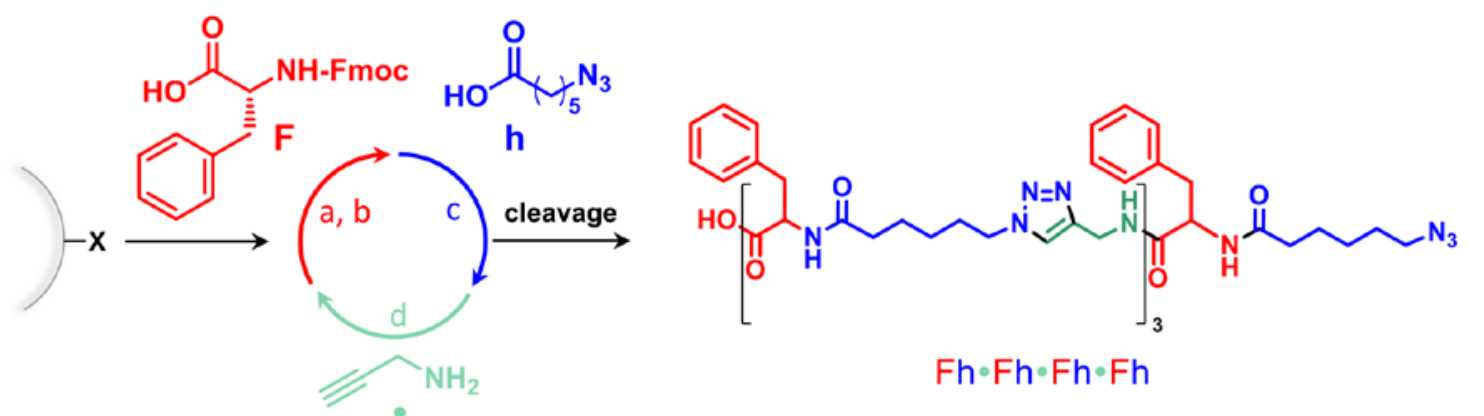

Figure 1. Schematic representation of the synthesis of the targeted macromolecule $(\mathrm{Fh} \bullet \mathrm{Fh} \bullet \mathrm{Fh} \bullet \mathrm{Fh}$ ) based on L-phenylalanine residues and aliphatic building blocks: a) Fmoc-LPhe-OH, HBTU, HOBt, DIPEA, anhydrous DMF, b) $25 \%$ piperidine in DMF, c) 6-azidohexanoic acid, HBTU, HOBt, DIPEA, anhydrous DMF, and d) propargylamine, $\mathrm{CuBr}$, PMDETA, anhydrous dichloromethane.

In the attempt to improve the synthesis of $\mathrm{Fh} \bullet \mathrm{Fh} \bullet \mathrm{Fh} \bullet \mathrm{Fh}$, various parameters known to be tunable to improve the synthesis of difficult peptides ${ }^{[14,15]}$ have been evaluated and the conditions used are listed in Table 1. The first hypothesis was that the conditions for the copperassisted alkyne-azide cycloaddition reaction were not optimal. Thus, step $\mathbf{d}$ was conducted using other conditions previously reported on solid support, ${ }^{[16]}$ i.e. in the presence of copper(II) sulfate, sodium ascorbate and DIPEA in DMF for $48 \mathrm{~h}$ (Table 1, Entry 2). These conditions did not afford the targeted macromolecule, i.e. absence of the molecular ion peak of $\mathrm{Fh} \bullet \mathrm{Fh} \bullet \mathrm{Fh} \bullet \mathrm{Fh}$ by ESI-MS. The second hypothesis was that the removal of the Fmoc group (step b) was incomplete, the concentration in piperidine of the deblocking solution was increased ${ }^{[17]}$ to $50 \%$ (Table 1, Entry 3) as compared to the solution previously used, ie. 25\% piperidine in DMF. This change did not seem to change significantly the results. The third hypothesis was that the coupling reaction for steps a and $\mathbf{c}$ was incomplete due to steric hindrance at the activated center on the growing chain. Thus, another coupling agent has been used, i.e. HBTU was replaced by 1-[bis(dimethylamino)methylene]-1H-1,2,3-triazolo[4,5-b]pyridinium 
hexafluorophosphate (HATU; Table 1, Entry 4), ${ }^{[18]}$ which unfortunately did not seem to improve the synthesis as compared to the initial condition (Table 1, Entry 1). The fourth hypothesis is that the coupling reaction for steps a and $\mathbf{c}$ was incomplete due to aggregation of the growing chain. Few conditions to overcome this potential problem of aggregation were evaluated included 1) reducing the loading density ${ }^{[19]}$ on the resin, i.e. the targeted loading of the resin with the first phenylalanine residue was half (Table 1, Entry 5), 2) improving the solvation of the growing chain by either adding dichloromethane, i.e. $1 / 1 \mathrm{DMF} / \mathrm{CH}_{2} \mathrm{Cl}_{2}$ (Table 1 , Entry 6), as $\mathrm{CH}_{2} \mathrm{Cl}_{2}$ has a superior capacity to swell the resin as compared to $\mathrm{DMF},{ }^{[20]}$ or adding chaotropic salts such as lithium chloride ${ }^{[21]}$ (Table 1, Entry 7), 3) conducting steps a and $\mathbf{c}$ under microwave irradiations $^{[22]}$ (Table 1, Entry 8) or 4) using a Tentagel resin ${ }^{[23]}$ (Table 1, Entry 9) that is reported to have a kinetic behavior of its reactive sites similar to those in solution chemistry. None of the attempts conducted to noticeable positive changes. Surprisingly, using the Tentagel seems to lead to even more residue deletions according to the ESI-MS spectrum. Finally, all of the reagents were pre-mixed before addition to the resin to pre-activate the carboxylic acid of Fmoc-Phe-OH (step a) and 6-azidohexanoic acid (step c). Using these last conditions the intensity of the peaks previously observed at 458.28, 799.47 and 1140.60 on the ESI-MS spectrum were significantly diminished (Figure $2 \mathrm{~b}$ ) as compared to the molecular ion peaks (i.e. $[\mathrm{M}+\mathrm{H}]^{+},[\mathrm{M}+\mathrm{Na}]^{+}$and $[\mathrm{M}+2 \mathrm{H}]^{2+}$ ). Furthermore, even though some peaks observed on the spectrum can be assigned to residue deletions, their intensities are clearly less pronounced.

Table 1. Synthetic conditions used for the preparation of the macromolecule $F \cdot \bullet F h \bullet F h \bullet F h$ based on L-phenylalanine (F) residues, 6-azidohexanoic acid (h) and propargylamine $(\bullet)$ as building blocks by solid-phase synthesis.

\begin{tabular}{cccl}
\hline Entry & $\begin{array}{c}\text { Loading } \\
\text { density }\end{array}$ & $\begin{array}{c}\text { Step } \\
\text { modified }\end{array}$ & Modifications as compared to reference [28] \\
\hline 1 & 0.45 & - & none \\
2 & 0.45 & $\mathrm{~d}$ & use of another copper catalyst $\left(\mathrm{CuSO}_{4} \cdot 5 \mathrm{H}_{2} \mathrm{O}\right.$, sodium L-ascorbate, DIPEA) \\
3 & 0.45 & $\mathrm{~b}$ & $50 \%$ piperidine in DMF used as deblocking solution \\
4 & 0.45 & a and c & HBTU replaced by HATU \\
5 & 0.29 & - & lower loading of the resin with $\mathrm{Fmoc}^{\mathrm{P}} \mathrm{Phe-OH}$ \\
6 & 0.62 & a and c & DMF was replaced by DMF/CH $\mathrm{Cl}_{2}(1 / 1)$ \\
7 & 0.62 & a and c & DMF was replaced by $0.4 \mathrm{M} \mathrm{LiCl} \mathrm{in} \mathrm{DMF}$ \\
8 & 0.62 & a and c & use of microwave irradiations \\
9 & 0.24 & - & 2-chlorotrityl chloride resin was replaced by Tentagel S PHB resin \\
10 & 0.62 & a and c & preactivation of carboxylic acids \\
\hline
\end{tabular}

calculated by gravimetry after functionalization of the 2-chlorotrityl chloride resin with Fmoc-Phe-OH, except for the experiment conducted on the Tentagel resin (Entry 9) for which the value provided by the supplier was used. 
a) "normal" conditions

\section{ESI-MS}

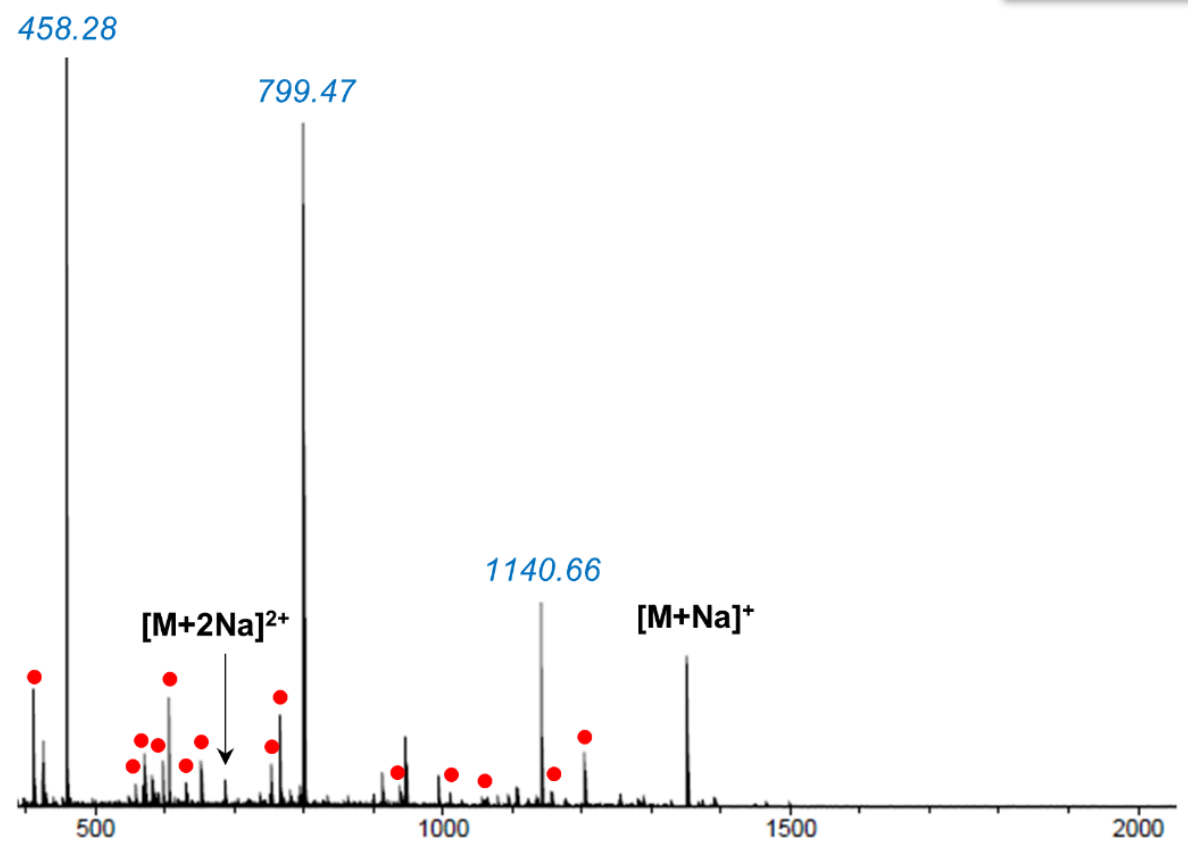

b) with preactivation of Fmoc-Phe-OH and 6-azidohexanoic acid

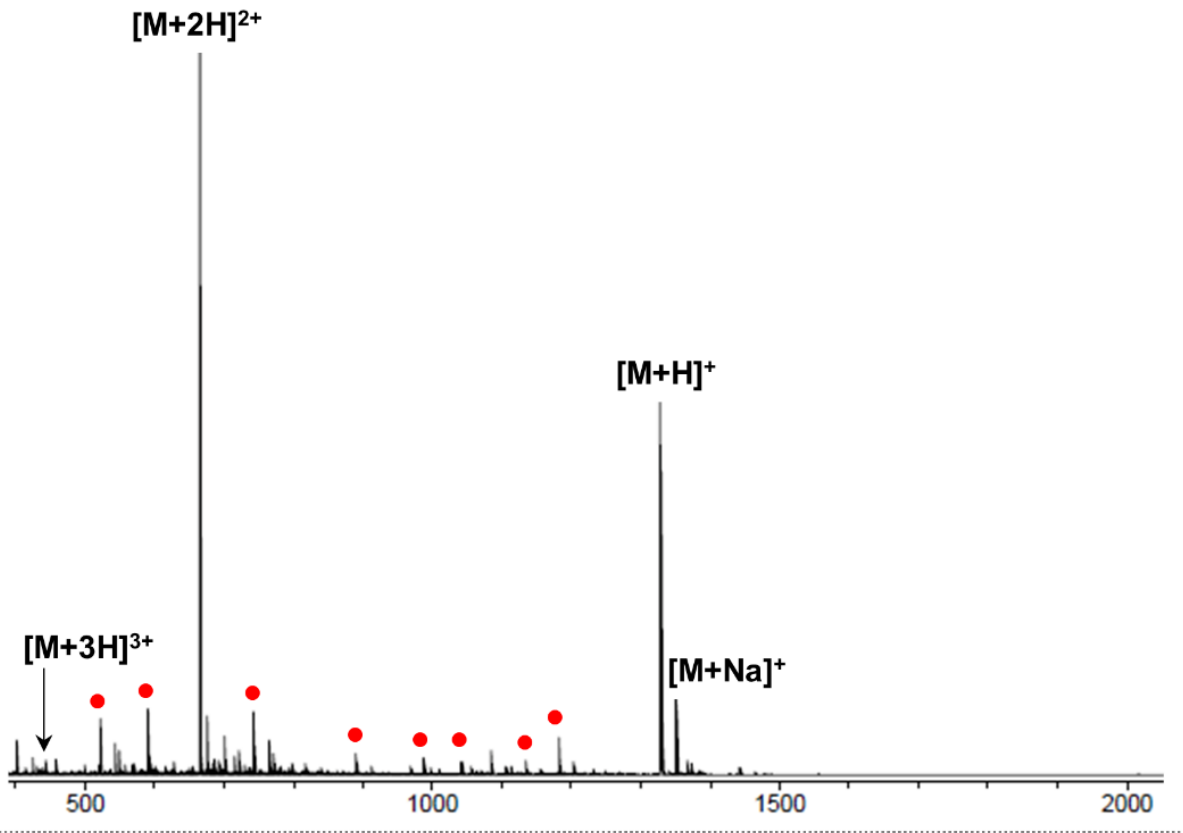

Figure 2. Characterization of $\mathrm{Fh} \bullet \mathrm{Fh} \bullet \mathrm{Fh} \bullet \mathrm{Fh}$ by mass spectrometry after electrospray ionization (ESI-MS): a) using the synthetic iterative procedure previously reported ${ }^{[12]}$ ("normal" conditions) and b) by modifying this procedure by preactivation of Fmoc-Phe-OH and 6-azidohexanoic acid in steps a and c respectively. The peaks identified as macromolecules with deletion residues are labeled with - (detailed assignment of these peaks in Table S1), while the undefined impurities are marked in blue. 
The thermal stability of this macromolecule is of importance since the working temperature during the preparation of the composite materials is above the melting temperature of the polymer matrix, e.g. the melting temperature of polypropylene being around $160{ }^{\circ} \mathrm{C}$, the working temperature to process the composite material should be at least $190{ }^{\circ} \mathrm{C}$. Thus to be suitable to be incorporated in polypropylene-based composite materials the synthesized macromolecule should not have any degradation pattern occurring at or below this working temperature. The TGA curve of Fh•Fh $\bullet F h \bullet F h$ (Table 1, Entry 10) displayed a first degradation at $78{ }^{\circ} \mathrm{C}$. On the TGA curve three weight losses were observed. The weight loss observed at $120{ }^{\circ} \mathrm{C}$ (3.45 wt\%) might be assigned to the loss of the terminal carboxylic acid of the macromolecule as the calculated weight loss of this terminus is estimated as $3.39 \mathrm{wt} \%$. Furthermore, when cumulated with the loss of $\mathrm{N}_{2}$ for each triazole and the terminal azide the calculated weight loss is estimated to $11.83 \mathrm{wt} \%$ that might be compared to the weight loss observed at $325^{\circ} \mathrm{C}$ at $11.06 \mathrm{wt} \%$. As phenylalanine has been reported to lose $98 \%$ of its weight at $400{ }^{\circ} \mathrm{C},{ }^{[24]}$ the main contribution of the weight loss observed between 320 and $525{ }^{\circ} \mathrm{C}$ was assigned to the thermal degradation of phenylalanine residues.

\section{Conclusions}

In summary, solid-phase synthesis was exploited as a synthetic strategy to prepare phenylalanine-based macromolecules that could be potentially used as interfacial agents in fiber-reinforced composite materials. Phenylalanine residues and synthetic aliphatic spacing units have been chosen as building blocks to promote a strong affinity with aramid fibers and a hydrophobic polymer matrix such as polypropylene respectively. The optimization of the reaction conditions for this synthesis was attempted to reduce the presence of molecules others

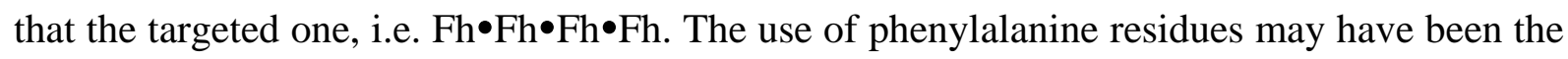
source of the difficulties encountered in the course of these iterative syntheses as phenylalanine $^{[25,26]}$ and short peptides containing phenylalanine residues ${ }^{[27-29]}$ have been previously reported to be able to self-assemble into structures such as fibril-like aggregates, nanotubes and helical ribbons. The deposition of these macromolecules on aramid fibers is currently under investigation.

\section{Supporting Information}

Supporting Information is available from the Wiley Online Library.

Acknowledgements: The research leading to these results has received funding from the H2020 program of the European Union (project Euro-Sequences, H2020-MSCA-ITN-2014, grant 
agreement no. 642083). The doctoral position of JL is supported by the project Euro-Sequences. The CNRS and PSA Groupe are also acknowledged for financial support. TGA data were obtained at the polymer characterization facilities of the Institut Charles Sadron. The authors thank Emeric Wasielewski (Cronenbourg NMR platform, UMR 7509) for the NMR measurements on the $500 \mathrm{MHz}$ spectrometer, Stéphanie Kouaho and Hélène Nierengarten (Service of Mass Spectrometry, GDS 3648) for the ESI-MS measurements and Mélanie Legros (Institut Charles Sadron) for the thermal analyses.

\section{References}

[1] N. Badi, D. Chan-Seng, J.-F. Lutz, Macromol. Chem. Phys. 2013, 214, 135.

[2] J.-F. Lutz, M. Ouchi, D. R. Liu, M. Sawamoto, Science 2013, 341, 1238149.

[3] S. C. Solleder, R. V. Schneider, K. S. Wetzel, A. C. Boukis, M. A. R. Meier, Macromol. Rapid Commun. 2017, 1600711.

[4] J.-F. Lutz, J.-M. Lehn, E. W. Meijer, K. Matyjaszewski, Nat. Rev. Mater. 2016, 1, 16024.

[5] C. Qu, J. He, Sci. China: Chem. 2015, 58, 1651.

[6] W. van Zoelen, H. G. Buss, N. C. Ellebracht, N. A. Lynd, D. A. Fischer, J. Finlay, S. Hill, M. E. Callow, J. A. Callow, E. J. Kramer, R. N. Zuckermann, R. A. Segalman, ACS Macro Lett. 2014, 3, 364.

[7] B. N. Norris, S. Zhang, C. M. Campbell, J. T. Auletta, P. Calvo-Marzal, G. R. Hutchison, T. Y. Meyer, Macromolecules 2013, 46, 1384.

[8] S. Zhang, N. E. Bauer, I. Y. Kanal, W. You, G. R. Hutchison, T. Y. Meyer, Macromolecules 2017, 50, 151.

[9] V. Meenakshisundaram, J.-H. Hung, T. K. Patra, D. S. Simmons, Macromolecules 2017, $50,1155$.

[10] V. Samsoninkova, B. Seidt, F. Hanßke, W. Wagermaier, H. G. Börner, Adv. Mater. Interfaces 2017, 4, 1600501.

[11] Han, O. Bas, C. Vaquette, G. Hochleitner, J. Groll, E. Kemnitz, D. W. Hutmacher, H. G. Borner, J. Mater. Chem. B 2017, 5, 5037.

[12] D. Chan-Seng, J.-F. Lutz, ACS Macro Lett. 2014, 3, 291.

[13] C. T. Choma, G. T. Robillard, D. R. Englebretsen, Tetrahedron Lett. 1998, 39, 2417.

[14] M. Quibell, T. Johnson, "Difficult peptides", in Fmoc solid phase peptide synthesis. A practical approach, W.C. Chan and P.D. White, Eds., Oxford University Press, New York, 2000.

[15] I. Coin, M. Beyermann, M. Bienert, Nat. Protocols 2007, 2, 3247.

[16] H. Fittler, O. Avrutina, B. Glotzbach, M. Empting, H. Kolmar, Org. Biomol. Chem. 2013, $11,1848$.

[17] G. B. Fields, "Methods for Removing the Fmoc Group", in Peptide Synthesis Protocols, M.W. Pennington and B.M. Dunn, Eds., Humana Press, Totowa, NJ, 1995, p. 17.

[18] F. Albericio, J. M. Bofill, A. El-Faham, S. A. Kates, J. Org. Chem. 1998, 63, 9678.

[19] K. C. Pugh, E. J. York, J. M. Stewart, Int. J. Pept. Protein Res. 1992, 40, 208.

[20] V. K. Sarin, S. B. H. Kent, R. B. Merrifield, J. Am. Chem. Soc. 1980, 102, 5463.

[21] A. Thaler, D. Seebach, F. Cardinaux, Helv. Chim. Acta 1991, 74, 628.

[22] F. Rizzolo, G. Sabatino, M. Chelli, P. Rovero, A. M. Papini, Int. J. Pept. Res. Ther. 2007, 13, 203.

[23] E. Bayer, M. Dengler, B. Hemmasi, Int. J. Pept. Protein Res. 1985, 25, 178.

[24] L. Xu, G. Xiao, C. Chen, R. Li, Y. Mai, G. Sun, D. Yan, J. Mater. Chem. A 2015, 3, 7498. 
[25] L. Adler-Abramovich, L. Vaks, O. Carny, D. Trudler, A. Magno, A. Caflisch, D. Frenkel, E. Gazit, Nat. Chem. Biol. 2012, 8, 701.

[26] T. D. Do, W. M. Kincannon, M. T. Bowers, J. Am. Chem. Soc. 2015, 137, 10080.

[27] M. Reches, Y. Porat, E. Gazit, J. Biol. Chem. 2002, 277, 35475.

[28] M. Pellach, S. Mondal, L. J. W. Shimon, L. Adler-Abramovich, L. Buzhansky, E. Gazit, Chem. Mater. 2016, 28, 4341.

[29] E. Mayans, J. Casanovas, A. M. Gil, A. I. Jiménez, C. Cativiela, J. Puiggalí, C. Alemán, Langmuir 2017, 33, 4036. 